\title{
MODERNIDADE E SOCIEDADE BRASILEIRA: "ENTUSIASMO”, “OTIMISMO” E INICIATIVAS LIBERTÁRIAS NA EDUCAÇÃO
}

\author{
Juliana Guedes dos Santos Marconi ${ }^{1}$ \\ Luiz Bezerra Neto ${ }^{2}$ \\ Universidade Federal de São Carlos (UFSCAR)
}

\section{RESUMO}

O contexto da modernidade exigiu um projeto de educação diferente. No Brasil, esse novo projeto, se fez tardiamente se o compararmos às civilizações européias, na transição do Império para a República concomitantemente com a expansão das lavouras cafeeiras, o crescimento industrial, a adoção do trabalho assalariado e a urbanização. Diante desse cenário dois movimentos ideológicos da elite permitiram que a educação se adequasse ao ritmo da modernidade. Os termos que até hoje os denominam foram cunhados por Jorge Nagle, em 1976, a saber: "entusiasmo pela educação" e "otimismo pedagógico". O primeiro, especialmente de caráter mais quantitativo, de expansão das escolas. O segundo, de cunho mais qualitativo, focalizando a reestruturação interna das escolas. Além disso, o cenário citado permitiu a chegada dos ideais anarquistas ao Brasil na bagagem de italianos e espanhóis, culminando inclusive na criação de escolas. O presente ensaio busca uma análise do panorama no qual os movimentos (os referidos "entusiasmo", "otimismo" e as iniciativas libertárias de educação concretizadas na cidade de São Paulo no início do século XX) permitiram-se atender à demanda de um projeto de educação adequado à nova situação social do país.

Palavras-chave: Modernidade; Anarquismo; Entusiasmo; Otimismo.

\section{MODERNITY AND BRAZILIAN SOCIETY: "ENTHUSIASM", “OPTIMISME" AND LIBERTARIAN INICIATIVES IN EDUCATION}

\begin{abstract}
The context of the modernity demanded a different project of education. In Brazil, this new project occurred tardily if compared with Europeans civilizations, in transition from the Emperor to the Republic, concomitantly with the expansion of coffee planting, the industrial growth, the adoption of paid work and urbanization. In the face of this scenery, two ideological movement of the elite allowed that education was adjusted to the rhythm of the modernity. The words that, till now name them were coined by Jorge Nagle, in 1976. They are: "enthusiasm for education" and "pedagogic optimism". The first had a character more specifically of scholar expansion. The second was more qualitative, focusing the intern restructuration of schools. Besides, the referred scenery allowed the arriving of anarchist ideals in Brazil, inside of Italians and Spanish luggage's, reaching the top in the creation of schools. The present essay aims an analysis of the panorama in which the movements (the referred "enthusiasm", "optimism" and the libertarian education initiatives, materialized in São Paulo at the beginning of XX Century) allowed attend the demand of a proper project of education, consonant with the new social situation of the country.
\end{abstract}

Keywords: Modernity; Anarchism; Enthusiasm; Optimism. 
A moderna sociedade surgiu do declínio da sociedade feudal. Na Europa, o processo se dá a partir da industrialização, da urbanização dos países, da ascensão da burguesia e da consolidação do capitalismo que vinha ocorrendo desde o século XV com as revoluções burguesa e Industrial. Segundo Franco Cambi, a Modernidade possui um "caráter revolucionário em relação a uma sociedade estática quanto às estruturas econômicas, quanto à organização social e ao perfil cultural como aquela que a precede: a Idade Média" (CAMBI, 1999, p. 195/196).

É no contexto da Modernidade que a Europa se abre para o mundo com as descobertas geográficas e seus comércios. É também neste panorama que se desenrolaram movimentos como as reformas religiosas, o renascimento cultural, o mercantilismo e a formação dos Estados Nacionais. Karl Marx e Friedrich Engels, no Manifesto do Partido Comunista, afirmam que

a descoberta da América e a circunavegação da África abriram um novo campo de ação para a burguesia nascente. Os mercados da Índia e da China, a colonização da América, o comércio com as colônias o aumento dos meios de troca e do volume das mercadorias em geral trouxeram uma prosperidade até então desconhecida para o comércio, a navegação e a indústria e, com isso, desenvolveram o elemento revolucionário dentro da sociedade feudal em desintegração (MARX \& ENGELS, 1998, p.9).

Ainda segundo esses autores "a burguesia submeteu o campo à cidade. Criou cidades enormes, aumentou prodigiosamente a população urbana em comparação com a rural e, dessa forma, arrancou uma grande parte da população do embrutecimento da vida do campo" (MARXS \& ENGELS, 1998, p. 12).

Os tempos eram outros e, aqui, a palavra "tempo" pode, além de caracterizar a época em que passava-se a viver, tratar da questão daquele tempo determinado pelo relógio. Isso porque o tempo passou a ter uma nova dimensão na vida das pessoas, pois a rotina do trabalho fabril, orientada por rígidas exigências, interferiu totalmente na sua forma de viver.

Cambi (1999, p. 197/198) afirma entender que as revoluções que decorreram do advento da Modernidade foram: a revolução econômica (supressão do sistema feudal pelo capitalista); a revolução política (nascimento do Estado moderno, centralizado); a revolução social (formação e afirmação da sociedade de classes); a revolução ideológicacultural (laicização e racionalização, Iluminismo) e, atrelada a esta última, a revolução pedagógica (formação do trabalhador fabril e dos intelectuais pela ótica iluminista, da qual trataremos mais tarde).

No Brasil, esse marco da passagem para a modernidade se deu com o processo de transição do Império para a República. Essa transição ocorreu concomitantemente com a expansão das lavouras cafeeiras, o crescimento industrial, a adoção do trabalho assalariado e a urbanização.

É com leis vindas de países nos quais a Modernidade já era fato consumado, que inicia-se o processo de transição do Império para a República no País. A partir de 1845, o imperialismo inglês passou a combater o tráfico negreiro, como explica Amarílio Ferreira Junior, pois, segundo o autor, 
o capitalismo britânico encarava as relações escravistas de produção mantidas em algumas regiões do mundo como um entrave à plena circulação das mercadorias produzidas pela revolução industrial, isto é, colocava dificuldades ao processo de acumulação acelerado do capital em decorrência da ausência de mão-de-obra assalariada (FERREIRA Jr., 2008, p. 58-59).

Além disso, em 1850, uma lei determinou que terras públicas somente poderiam ser adquiridas por meio de contrato de venda e compra colocando fim ao processo de obtenção das terras mediante ocupação, arrendamento e meação. Essa lei também determinou que as taxas de registro de propriedade cobradas pelo Estado serviriam para financiar as novas demarcações de terras públicas e também para subvencionar a imigração de colonos livres estimulando assim, a abolição da escravidão. Além disso, a Lei da Terra, como ficou conhecida, elevou os preços das terras públicas fazendo com que os imigrantes, recém-chegados e com dificuldades de adquirir terras, acabassem por se tornar mão-deobra assalariada.

Pode-se dizer, portanto, que a abolição da escravidão brasileira foi o resultado da imposição da lógica capitalista mundial associada à manutenção da propriedade privada da terra, dos latifundiários.

Aqui, um ponto fundamental diferencia o processo de transição para a Modernidade na Europa e no Brasil: a imigração. Com a abolição da escravidão africana no País abriu-se caminho para os primeiros trabalhadores assalariados, os imigrantes europeus e japoneses. Embora tenha-se notícia de contratação de mão de obra estrangeira anterior à abolição da escravidão africana, como a de Nicolau Campos Vergueiro que "em 1840 introduziu em sua fazenda [em São Paulo] oitenta famílias de portugueses, colonos livres, que começaram a viver e a trabalhar junto com o elemento servil" (BEZERRA, 2001, p. 34), é com a assinatura da Lei Áurea em 1888 que vemos ampliada a demanda por mão de obra e o aumento significativo das contratações de estrangeiros.

Segundo Jorge Nagle, "a imigração foi elemento importante na alteração do mercado de trabalho e das relações trabalhistas, e representou nova modalidade de força de trabalho, qualitativamente diferente daquela formada nos quadros da produção escravagista" (NAGLE, 1976, p. 24).

Como afirma Nagle (1976), pelo fato de a Federação traduzir no plano político as condições objetivas da estrutura agrária dominante, o Brasil fez-se, na Primeira República, um País dominado pelo Coronelismo que, por implementar uma determinada forma de mandonismo a partir das relações de poder local, frustrava qualquer modificação na estrutura política do país.

No setor econômico, havia o crescimento das lavouras cafeeiras reforçadas pelas relações coronelistas dos maiores estados produtores do chamado "ouro verde" (Minas Gerais e São Paulo). Segundo Nagle, "o café era a principal mercadoria para recursos no comércio exterior, e a industrialização a grande esperança para a superação da economia colonial" (NAGLE, 1976, p. 17).

Dessa forma, inerente ao desenvolvimento da produção cafeeira, segundo Nagle gera-se a industrialização brasileira cujo desenvolvimento não foi simples e nem rápido. Um dos entraves à industrialização foi o movimento do ruralismo que representa, nas palavras de Nagle, a 
defesa da "natural" civilização agrária, [onde] os interesses nela implicados se metamorfoseiam em diferentes formas de atuação e de pensamento, desde as de natureza técnico-econômica (...) até os de natureza ideológica - por exemplo, a idéia de que a felicidade do homem brasileiro esteve e está ligada ao meio rural, fonte de energia, de saúde, de pureza de costumes (NAGLE, 1976, p. 15).

Ainda que com certa dificuldade, a industrialização brasileira se fez na transição do Império para a República superando o ruralismo, mas originando-se no interior das lavouras cafeeiras. Segundo Nagle

a expansão da lavoura cafeeira, a transformação do fazendeiro do café em empresário e a conseqüente decadência da velha classe aristocrática vão formar o grande quadro em que se desenrolarão importantes fenômenos histórico-sociais [...] Transformados em empresários, os fazendeiros do café incentivarão o surgimento de uma nova classe mercantil, até no sentido de fazê-la funcionar no ramo do alto comércio ligado ao mercado interno; além disso, é da empresa cafeeira que vai surgir a nova classe ligada à industrialização (NAGLE, 1976, p. 27).

Ao passo, portanto, que a Modernidade se concretiza no Brasil, surgem, no campo social, as relações de classe típicas modernas, ou seja, relações entre burgueses e proletários. Estes últimos se fizeram muito presentes na Primeira República e foram, de certa forma, formados pela influência estrangeira dos imigrantes. De acordo com Jorge Nagle

com o novo surto industrial e com o desenvolvimento da urbanização, os imigrantes começaram a ser atraídos para os novos núcleos urbanoindustriais, quando colaboraram para acelerar a passagem das atividades artesanais para as industriais [...] Tendo colaborado nos processos de urbanização e de industrialização, o imigrante foi responsável pela difusão de novas idéias no campo social, do que é amostra a sua participação ao longo do movimento das chamadas "lutas sociais", desencadeado durante o período da República Velha (NAGLE, 1976, p. 24)

Tais lutas foram mais expressivas a partir das iniciativas propostas pelos anarquistas italianos e espanhóis, que trouxeram em suas bagagens, fartas experiências de lutas. Nas palavras de Nagle (1976), as ideias anarquistas

são predominantes nos dois primeiros decênios deste século [o século $\mathrm{XX}]$; o anarquismo domina porque, ao contrário do que ocorria com o socialismo, seus líderes não ficaram só na pregação, mas orientaram-se para a ação - principalmente greves [...] O movimento anarquista no Brasil, portanto, se desenvolve nas praças públicas e organizações de classe (NAGLE, 1976, p.36/37).

Entretanto, foi com o movimento Nacionalista que os imigrantes e, por consequência, parte das lutas operárias, sofreram as maiores repressões. Segundo Nagle era Revista HISTEDBR On-line, Campinas, n.46, p. 205-218, jun2012 - ISSN: 1676-2584 208 
estimulado "o combate às doutrinas libertárias e subversivas, sustentando a fórmula "contra o anarquismo, o nacionalismo"” (NAGLE, 1976, p. 52). O autor comenta ainda que

\begin{abstract}
no conjunto das idéias coibitivas dos poderes públicos, há algumas particularidades que devem ser lembradas. De modo geral, o combate ao socialismo, ao anarquismo e ao comunismo foi uma luta contra o que se considerava o "anarquista". A palavra, na linguagem oficial, não comportava elementos doutrinários, isto é, não era empregada em sentido técnico; o significado era o do senso comum. Anarquistas poderiam ser os próprios anarquistas, tanto quanto os socialistas e comunistas, bem como quaisquer pessoas que perturbassem a tranqüilidade da ordem pública (ou, melhor, de determinados públicos). Também ficou estabelecida, desde cedo, a relação entre os anarquistas e estrangeiros; com isso, coibir as atividades do socialismo e, especialmente, do anarquismo e do comunismo, era o mesmo que cercear a atividade do estrangeiro (NAGLE, 1976, p. 40).
\end{abstract}

Esse cerceamento ao estrangeiro se deu principalmente com o estabelecimento da proibição da contratação de trabalhadores oriundos de outros países acima da cota permitida para cada empresa.

\title{
Panorama Educacional
}

A transição do mundo feudal para o moderno, marcado pelas revoluções burguesas, pelas reformas religiosas, pelo renascimento cultural, pelo mercantilismo e pela formação dos Estados Nacionais, bem como a Revolução Industrial, demandou um novo projeto de educação para a sociedade que se formava em virtude das mudanças na organização social do trabalho, e na vida em social cheia de novos hábitos.

Uma das características que, nesse período, modificaram a vida em sociedade foi a questão do tempo e da disciplina.

Como dito, a diferenciação da noção de tempo, resultado do aceleramento do ritmo de vida moderno, também foi determinante no novo projeto educacional da modernidade. Não havia mais tempo hábil para uma aprendizagem artesanal como a ministrada nas corporações da Idade Média. Era necessário que a educação fosse agilizada tal como o modo de produção e o ritmo de vida das pessoas. Dessa forma, como afirma Mario Alighiero Manacorda, "fábrica e escola nascem juntas: as leis que criam a escola de Estado vêm juntas com as leis que suprimem a aprendizagem corporativa" (MANACORDA, 2002, p. 249).

Além disso, vê-se que a educação proferida pela Igreja Católica sofre um certo declínio, resultado das reformas religiosas favorecendo assim, o surgimento da educação laica e estatal. Esta, por sua vez, influenciada fortemente pelo Iluminismo, traz um novo conceito de cidadão que se opunha aos conceitos anteriores: onde o cidadão seriam homens, proprietários de terra e não estrangeiros (Antiguidade) e onde o cidadão seria o bom cristão (Idade Média). O conceito de cidadão na modernidade abrange também dois sujeitos que se impõem - as mulheres e o povo. Nos dizeres de Franco Cambi, "segue-se o modelo [de formação] do Homo faber e do sujeito como indivíduo, embora ligando-o à 'cidade' e depois ao Estado [...] muda-se portanto, os fins da educação destinando-se esta a 
um indivíduo ativo na sociedade, liberado de vínculos e de ordens" (CAMBI, 1999, p. 198 - grifo do autor).

Dessa forma, a escola passa a ocupar "lugar cada vez mais central, cada vez mais orgânico e funcional para o desenvolvimento da sociedade moderna" (CAMBI, 1999 p. 199).

Quanto à disciplina, também foi marcante sua presença nos novos conceitos educacionais. Isso relaciona-se também com o caráter funcional da escola apontado por Cambi onde a escola, assemelhando-se à fábrica e a exemplo de sua tecnicidade, passa a ser mais sistemática e a organização dos conteúdos em função do tempo que se passa na escola tornou-se objeto de pesquisa de muitos autores.

No período estudado, duas obras cuja pretensão era regular a educação demonstram de forma muito clara tal sistematização e, além disso, retratam os dois pensamentos pedagógicos característicos da época. São elas: Didática Magna: Tratado da arte Universal de ensinar tudo à todos de Jan Amos Comenius (1657) e a Ratio Studiorum (1599) aprovada pelos jesuítas e baseada em São Tomás de Aquino.

Tais obras padronizaram a conduta das pessoas que frequentavam as escolas, fossem elas alunos ou professores. Além disso, mantinham em certo grau a presença da Igreja na educação, ainda que tal influência tenha sido fortemente diminuída pela presença do Estado nos países que não se conservaram católicos após a Reforma.

Ainda sobre a organização da nossa produção, temos outras iniciativas no campo educacional que seriam determinantes para o panorama educacional do início do século XX e, portanto, da Modernidade brasileira. Foram eles: o Ato adicional de 1834 que descentralizou o ensino primário que, por consequência, foi relegado ao abandono por falta de estrutura financeira das províncias, a estruturação do ensino secundário para as elites e a fundação do Colégio Pedro II que seria o principal instrumento de acesso ao Ensino Superior.

Até então, como vimos, a educação estava arraigada aos conceitos de elitismo e exclusão. E nesse sentido, o panorama não seria muito alterado na República ainda que fosse ampliada a demanda educacional pela presença dos novos sujeitos da Modernidade principalmente os trabalhadores fabris.

Fator determinante para a educação que estaria por vir com o advento da república foi o movimento, denominado por Jorge Nagle de fervor ideológico que, segundo o autor, representava uma

profunda e vigorosa discussão havida no final do Império a propósito dos assuntos educacionais. Abrangia uma tomada de decisão diante das precárias condições do sistema escolar até então existente, nos seus vários graus e ramos, avançando-se na formulação de uma política nacional de educação (NAGLE, 1978, p. 261).

Segundo Paulo Ghiraldelli Jr. (1987), não houve intervenções práticas que alterassem o cenário, mas o "vigoroso movimento de ideias" denunciava a realidade nada animadora de uma situação de insuficiência na situação do ensino básico.

Em meio a esse fervor ideológico, segundo Dermeval Saviani (2006, p. 27), ocorreu a direção tomada na última iniciativa política educacional do Império brasileiro (em 19/04/1879, com a Reforma Leôncio de Carvalho): o método intuitivo que, embora tenha se originado em meio ao modo feudal de produção, tornar-se-ia dominante na Revista HISTEDBR On-line, Campinas, n.46, p. 205-218, jun2012 - ISSN: 1676-2584 
Primeira República sendo contestado apenas por volta de 1920 com o movimento da Escola Nova de que trataremos mais tarde.

Dermeval Saviani também coloca que foi durante a transição do modo feudal de produção e a modernidade, que começamos e ver em terras brasílicas o que realmente eram as escolas. Segundo o autor, apesar das inúmeras iniciativas educacionais, não se podia falar em escola em termos de estrutura uma vez que os governos apenas normatizavam "pela via legal, os mecanismos de criação, organização e funcionamento de escolas que, por esse aspecto adquiriam o caráter de instrução pública. Mas, de fato, essas escolas continuavam funcionando em espaços privados, a saber, as próprias casas dos professores" (SAVIANI, 2006b, p. 17).

No final do século XIX, com o início do regime Republicano as escolas ganham uma nova "forma". A reforma da instrução pública paulista (mas que, posteriormente, se estendeu aos demais estados) iniciada pela iniciativa de Caetano de Campos (Diretor da Escola Normal de São Paulo) e Rangel Pestana acabou por culminar em lei que previa entre outros fatores a criação de grupos escolares. Esses grupos reuniam várias turmas de acordo com o nível de ensino, sendo também chamados de escolas graduadas.

O movimento dos Grupos Escolares, ou escolas graduadas, só fez crescer e atravessou a virada do século ampliando-se para o interior do estado paulista e para os demais estados brasileiros. Segundo Saviani, a graduação do ensino proposta pelos Grupos Escolares garantia uma "mais eficiente divisão do trabalho escolar, ao formar classes com alunos de mesmo nível de aprendizagem. E essa homogeneização do ensino possibilitava um melhor rendimento escolar" (SAVIANI, 2006b, p. 30). Entretanto,

em contrapartida, essa forma de educação conduzia, também, a mais refinados mecanismos de seleção, com altos padrões de exigência escolar, "determinando inúmeras e desnecessárias barreiras à continuidade do processo educativo", o que acarretava "o acentuado aumento da repetência nas primeiras séries do curso" (SAVIANI, 2006b, p. 30).

Porém, ainda segundo Saviani, ao discutir a graduação do ensino através do grupo escolar, este afirma que,

trata-se, pois, de um modelo que se foi disseminando por todo o país, tendo conformado a organização pedagógica da escola elementar que se encontra em vigência, atualmente, nas quatro primeiras séries do ensino fundamental. Com certeza é esse o principal legado educacional que a fase inicial do "longo século XX" nos deixou (SAVIANI, 2006b, p. 29).

Associado à estruturação do ensino primário a criação das Escolas Normais garantiram uma organicidade entre a formação dos professores e as escolas que eram criadas. Entretanto, a criação das Escolas Normais acabou por reforçar o caráter elitista da educação ao passo que apenas as moças das camadas mais abastadas ingressavam no magistério.

Segundo Ghiraldelli Jr., após 1915, houve campanhas e frentes "para desenvolver o sistema escolar e democratizar o acesso ao ensino básico [...] num movimento carregado de ideias cívicas, patrióticas, nacionalistas, onde a questão da difusão da escola popular, a 
escola primária, aparecia de forma relevante" (GHIRALDELLI Jr., 1987, p. 25) originando um verdadeiro "entusiasmo pela educação".

Este termo ("entusiasmo pela educação") foi cunhado por Jorge Nagle em 1976 e representa uma iniciativa especialmente de caráter mais quantitativo, de expansão das escolas. Ocorreu, principalmente, entre os anos de 1887 e 1896 (com o fervor ideológico já citado) retornando, em sua melhor fase (e a partir da insatisfação dos próprios republicanos com a República existente), após o término da Primeira Guerra Mundial e permanecendo nas duas primeiras décadas do século XX.

Nas palavras de Nagle o "entusiasmo" "trata-se de um movimento de 'republicanização da República' pela difusão do processo educacional - movimento tipicamente estadual, de matiz nacionalista e principalmente voltado para a escola primária, a escola popular" (NAGLE, 1978, p. 262).

O movimento do Nacionalismo representou, portanto, com o "entusiasmo", iniciativas educacionais relevantes. Nas palavras de Nagle,

as primeiras manifestações nacionalistas apareceram, de maneira mais sistemática e mais influenciadora, no campo da educação escolar, com a ampla divulgação de livros didáticos de conteúdo moral e cívico ou, melhor, de acentuada nota patriótica (NAGLE, 1976, p. 44)

A importância dada à educação pelos nacionalistas também é explicitada por Jorge Nagle, a partir do momento em que são "estabelecidas as duas coordenadas básicas do movimento - o serviço militar, para fazer frente ao perigo externo, e a instrução, para combater o perigo interno - a pregação nacionalista centralizar-se-á na formação da consciência nacional" (NAGLE, 1976, p. 46), ou seja, enquanto disseminação das correntes ideológicas da época.

Em 1919, segundo Ghiraldelli Jr., a Liga Nacionalista do Brasil incluía em seus objetivos a difusão do ensino popular quando dizia ser necessário "junto ao combate à abstenção eleitoral [e as fraudes que corrompiam e viciam o exercício do voto] deveria seguir o projeto da difusão do ensino popular, pois o analfabetismo era o principal responsável - segundo a Liga - pelo monopólio do poder encarnado nas oligarquias" (GHIRALDELLI Jr. 1987, p. 27).

Essa questão relacionada ao voto também foi abordada por Nagle, quando este diz que, segundo a nova formulação nacionalista "constitui absurdo [...] o fato de que a vontade nacional seja representada por apenas trinta e cinco por cento da população [...] Por isso, impõe-se o combate ao analfabetismo [...] Daí decorre o esforço para disseminar a instrução popular" (Nagle, 1976, p. 48).

Após 1924 com o aumento da presença do imperialismo americano no Brasil através de empréstimos públicos e instalações de empresas subsidiárias (como a General Motors) veio também o imperialismo cultural. Segundo Ghiraldelli Jr., "na educação as idéias da Pedagogia Nova, sob o regrário dos escritos de Dewey, Kilpatrick e outros, ganharam força nos anos 20, chegando a direcionar os intelectuais liberais" (GHIRALDELLI Jr., 1987, p. 30).

Ghiraldelli Jr. ainda nos explica que estas ideias associaram-se aos

princípios e posturas das elites intelectuais em relação à questão do tema da educação nacional assim, no final dos anos de 1920 a questão da 
alfabetização das massas parecia querer ceder um lugar para um movimento que considerava mais relevante a reestruturação interna das escolas, as mudanças dos conteúdos e métodos pedagógicos, a introdução de técnicas pedagógicas com a moderna psicologia (GHIRALDELLI JR. 1987, p. 31).

Isso porque como dito, durante os anos de 1910, o "entusiasmo pela educação" caracterizava uma preocupação quantitativa com a educação. Já nos anos de 1920, com tal "otimismo pedagógico" a preocupação com a educação passava a ser mais qualitativa e representaria, segundo Nagle, a "disputa entre os modelos da 'escola tradicional' e da "escola nova", (NAGLE, 1978, p. 264).

O termo "otimismo pedagógico" também foi cunhado por Nagle em 1976 e, tal movimento, segundo o próprio autor,

\begin{abstract}
apresentando-se como uma verdadeira "revolução copernicana" no campo da educação, o escolanovismo pretende deslocar o educando para o centro das reflexões escolares. Daí resultar em profunda alteração dos padrões em que se sustentava a chamada "escola tradicional": são novos valores e princípios a fundamentar a organização escolar, novos modelos de relacionamento entre professor e alunos, novo significado das matérias ou disciplinas, novos métodos. Enfim, novo modelo (NAGLE, 1978, p. 265).
\end{abstract}

Ghiraldelli Jr. ainda ressalta que "as teses inspiradas na Pedagogia Nova vinham mescladas com uma excessiva preocupação com as questões da higiene, da sexualidade, da saúde; além disso, também estavam presentes os tradicionais temas referentes à educação cívica, educação moral, patriotismo, etc” (GHIRALDELLI Jr., 1987, p. 34).

Em dezembro de 1931, segundo Saviani, durante a IV Conferência Nacional de educação, o chefe do governo provisório, Getúlio Vargas "solicitou aos presentes que colaborassem na definição da política educacional do novo governo" (SAVIANI, 2006b, p. 34), o que além de tumultuar a Conferência, resultou na resposta em forma de manifesto em março de 1932. Era o Manifesto dos Pioneiros da Educação Nova, maior expressão do "otimismo", dirigido ao governo e à população e que

propunha-se a realizar a reconstrução social pela reconstrução educacional. Partindo do pressuposto de que a educação é uma função essencialmente pública, e baseado nos princípios da laicidade, gratuidade, obrigatoriedade, co-educação e unicidade da escola, o manifesto esboça as diretrizes de um sistema nacional de educação, abrangendo de forma articulada, os diferentes níveis de ensino, desde a educação infantil até a universidade (SAVIANI, 2006b, p. 33).

Tal documento influenciaria a Constituição de 1934 e marcaria, no entendimento deste ensaio, a passagem da Primeira para a Segunda República.

Todo esse cenário de industrialização, de substituição gradual da mão-de-obra escrava pelo trabalho assalariado dos imigrantes, de urbanização e de fervor ideológico permitiu que os ideais anarquistas de educação chegassem ao País na bagagem dos 
italianos e espanhóis e a difusão de tais ideias que culminou inclusive na criação de algumas escolas com a marca dos anarquistas. Sobretudo, as escolas modernas.

As concepções anarquistas de educação manifestadas no Brasil foram inspiradas nos ideais de Francisco Ferrer y Guardia que, em Barcelona, em 1901, fundou La Escuela Moderna que, mais tarde também resultou num livro homônimo que narra a trajetória da instituição.

No livro La Escuela Moderna (2005) Ferrer afirma que o objetivo, ou nas palavras do próprio autor, a missão da escola era a formação completa e racional da criança enquanto indivíduo inserido na sociedade.

Além dessa diretriz, a obra de Ferrer retrata também uma profunda preocupação com fatores que estão presentes na convivência em sociedade e na vivência escolar como a desigualdade social, o ensino religioso, a co-educação dos sexos, o cuidado com a higiene e a presença das famílias na escola.

A necessidade da co-educação de ambos os sexos foi justificada por Ferrer a partir da situação de submissão da mulher na sociedade patriarcal. Além disso, na concepção libertária, segundo Anastasio Ovejero Bernal, a educação deve ser fundada "no princípio da igualdade natural dos homens, de que se deriva a exigência do desenvolvimento de todas as suas possibilidades e que pretende formar na criança uma personalidade equilibrada e afastada de todo preconceito e de todo dogmatismo" (BERNAL, 2006, p. 15).

Quanto à questão da desigualdade social, o autor coloca que a educação de crianças ricas não pode ser racional se é exclusivista e se, pela força do valor dado às coisas, ensina a conservação do privilégio. Para ele, a educação de pobres e ricos, por colocar em contato uns com os outros acaba por ser boa, necessária e reparadora.

A questão da higiene é tratada a fim de conscientizar os alunos de que a sujeira pode trazer doenças além de um prejuízo de socialização uma vez que se repugna qualquer objeto, animal ou pessoa suja. A importância dessa consciência, segundo o autor é a repercussão que se dá nas casas dos alunos que chegam a mudar a rotina da família. A higiene do ambiente escolar era fundamental para a conscientização dos alunos e era explicada como fator de "proteção da escola".

Ao se atentar ao fato de que todo o sistema de educação espanhol estava, na época de Ferrer, nas mãos da Igreja Católica percebemos a não aceitação da questão da religião nos princípios da Escola Moderna. Além disso, havia uma relação de prêmios e castigos abominada pelos libertários e muito presente na religião como forma de garantia de boa conduta das pessoas.

Já para garantir a presença das famílias na escola, Ferrer sugeriu a organização de conferências dominicais públicas que se dedicassem à instrução popular e acolhessem alunos, familiares e outros trabalhadores que desejassem aprender. Tais conferências ganharam mais forma com o tempo e se normalizaram constituindo cursos científicos que tratavam de temas de interesse comum de forma que todos os ouvintes, independente da idade, compreendessem.

Foi no estado de São Paulo, onde mais se criou escolas enquanto iniciativa libertária. Pelo interior já se haviam criado várias escolas como em Campinas, Franca e Sorocaba, por exemplo. Entretanto, segundo Ghiraldelli Jr. (1987, p. 128), com o fuzilamento de Francisco Ferrer (grande propulsor do ideário educacional anarquista) em 1909, intensificaram-se as iniciativas e deu-se início a um movimento que tinha por 
objetivo criar escolas nos moldes das que Ferrer havia dirigido na Espanha dando assim prosseguimento à sua obra. Seus nomes também não mudariam: Escolas Modernas.

Depois de inúmeras iniciativas para angariar fundos para a criação dessas escolas, foram fundadas em 13 de maio de 1912 as primeiras duas unidades da Escola Moderna em São Paulo. Segundo Ghiraldelli Jr. (1987, p. 133) ficaram como responsáveis dos estabelecimentos João Penteado e Adelino de Pinho respectivamente às Escolas no 1 e n ${ }^{\circ} 2$.

Os periódicos, tão importantes na disseminação dos ideais anarquistas, também estavam presentes na metodologia das escolas. Segundo José Damiro de Moraes, foi criado junto com a escola o jornal "O Início" que era "escrito e dirigido pelos alunos da Escola Moderna, visando divulgar os trabalhos preparados e fornecer informações das atividades sociais" (MORAES, 1999, p. 46).

Porém, apesar dos trabalhos bem desenvolvidos e do empenho bem sucedido das Escolas Modernas, um incidente pôs fim à experiência da educação libertária em São Paulo. A frequente repressão de setores da Igreja e do governo paulista acabou por vencer as iniciativas educacionais quando, segundo Ghiraldelli Jr., "em outubro de 1919 uma bomba explodiu no interior de uma casa no Brás, matando quatro anarquistas [...] a imprensa conservadora fez questão de concluir que a explosão nada mais era do que um "erro de cálculo nos planos anarquistas de tomar o poder"' (GHIRALDELLI Jr., 1987, p. 138).

Isso bastou para que, segundo o autor (1987, p. 138), ainda em 1919 “o Diretor Geral da Instrução Pública de São Paulo, alegando que as Escolas Modernas não cumpriam com as exigências de funcionamento" (GHIRALDELLI Jr., 1987, p. 138) fechasse os estabelecimentos.

Ainda Segundo Ghiraldelli Jr.,

no mesmo dia em que recebeu a ordem de fechamento das escolas, João Penteado entrou com um habeas-corpus no Tribunal de Justiça de São Paulo, em seu nome e em nome dos setenta alunos existentes na escola naquela data. $\mathrm{O}$ tribunal paulista negou o habeas-corpus por unanimidade (GHIRALDELLI Jr., 1987, p. 138).

O professor ainda recorreu, segundo o autor, ao Supremo Tribunal Federal onde seu habeas-corpus também fora negado, mas recebeu o apoio do ministro Sebastião Lacerda que, por sua vez, com o apoio dos ministros Pedro Miebelli e Lins de Albuquerque, defendeu o professor João Penteado alegando em seu discurso que: "o fato de ser anarquista "não constituía motivo para que sua escola fosse fechada pela violência do governo paulista'" (GHIRALDELLI Jr., 1987, p. 138/139).

Ainda segundo o autor (1987, p. 139), João Penteado lutou judicialmente com todas as forças para reabrir as Escolas Modernas, chegou inclusive a mandar uma carta ao ministro do Tribunal de Justiça de São Paulo. "Num dos trechos da carta, Penteado procurava demonstrar que as diferenças ideológicas entre ele e o ministro se explicavam pela origem de classe" (GHIRALDELLI Jr., 1987, p.139). Entretanto, acabou vencido e as escolas modernas fechadas.

\section{Conclusão}


Buscou-se neste ensaio uma análise do panorama no qual os movimentos expostos ("entusiasmo pela educação", "otimismo pedagógico" e as iniciativas libertárias de educação concretizadas na cidade de São Paulo nas primeiras décadas do século XX) permitiram-se atender à demanda de um projeto de educação adequado à nova situação social do País decorrente da Modernidade e suas implicações.

Salvo as diferenças de data, podemos inicialmente considerar que o panorama que permitiu (na Europa e no Brasil) a transição da sociedade feudal para a moderna acaba sendo muito parecido devido a consolidação do capitalismo atrelado à industrialização e à urbanização.

Vimos que é com o fim da mão-de-obra escrava e a adoção do trabalho assalariado que a sociedade se moderniza ao passo que a população é levada a se concentrar nas cidades e não mais no campo. Com esse processo de urbanização decorrente da industrialização, os trabalhadores, antes rurais, passam a conviver nas fábricas.

Assim, se fez necessária a expansão das escolas pela necessidade de uma instrução mínima aos trabalhadores fabris emergentes do novo modo de produção e, através da consolidação dos Estados-nação, a estatalidade educacional começa a existir num cenário antes dominado pela Igreja Católica. As Reformas religiosas, principalmente reivindicadas por Martinho Lutero, também chamavam ao Estado a responsabilidade pela educação.

Essa expansão foi garantida em parte, no Brasil, com o movimento do "entusiasmo pela educação" ainda que a educação difundida fosse incompatível qualitativamente com as necessidades da formação do cidadão.

Vimos também que é com a formação do proletariado fabril no mundo e, com a presença dos imigrantes no Brasil, que surgem as iniciativas libertárias de educação, alternativas às propostas confessionais e Estatais.

Entretanto, é também com a consolidação do capitalismo que a sociedade de classes se evidencia e, consequentemente aumenta a repressão da burguesia para com o proletariado, suas lutas e reivindicações. Exemplo disso é a repressão feita às iniciativas libertárias de educação no Brasil que, como Nagle (1976) acentuou, representavam, de certa forma os ideais de socialistas e comunistas julgados da mesma forma, como comprometedores da ordem pública, pelo governo nacionalista.

Porém, é necessário dizer que, talvez pela proximidade, em alguns, pontos entre as iniciativas libertárias e o movimento do "otimismo pedagógico", concretizado pelo Manifesto dos Pioneiros da Educação Nova em 1932, a educação libertária conseguiu, ainda que indiretamente influenciar as propostas educacionais nacionais, pelo menos em suas aspirações.

Isso porque, embora o "otimismo" tenha sido um movimento incitado pela elite brasileira, em muitos pontos ele se assemelha às proposições da pedagogia libertária e, ao contrario dos anarquistas, conseguiu colocar em prática muitas de suas reivindicações ainda que, segundo Paschoal Leme, um dos signatários do Manifesto de 1932, citado por Ferreira Jr., tenha dito que ao que parece, o Manifesto foi avançado demais para a época. Segundo o próprio Lemme

se o que propusemos e pregamos foi considerado por muitos como por demais avançado ou até mesmo utópico para a época, respondemos que sem essa visão ampla de futuro a educação não tem sentido, pois ela é, 
antes de tudo, o instrumento que, partindo de uma consideração clara da situação presente, se projeta no porvir, como uma antecipação de tempos vindouros, pois se destina à formação dos homens que viverão em outras épocas e em novos tempos (LEMME 2004, p. 155, apud FERREIRA Jr., 2008, p. 79).

Ferreira Jr. ainda completa que "podemos concluir que Paschoal Lemme tinha razão. Pois, estamos ainda esperando as 'outras épocas e os novos tempos', já que muito dos princípios educacionais propostos pelo 'Manifesto' ainda não foram levados à prática em pleno início do século XXI” (FERREIRA Jr., 2008, p. 79).

Concluímos, portanto, que os movimentos estudados neste ensaio ("entusiasmo", "otimismo" e iniciativas libertárias concretizadas no Brasil no início do século XX) conseguiram, ainda que não plenamente ou de forma ideal, atender à necessidade educacional que a Modernidade demandou.

Embora não tenhamos conseguido uma real democratização do ensino no País, o "entusiasmo pela educação" conseguiu ampliar o acesso à escola. Embora não tenhamos conseguido um ideal de qualidade educacional, o "otimismo pedagógico" conseguiu alterar, ainda que pouco, a metodologia das escolas e, principalmente, revigorar as discussões acerca do tema que não deixaram de ser objetos de estudo até os dias de hoje. Embora as iniciativas libertárias de educação tenham sido violentamente reprimidas e injustamente julgadas, elas conseguiram concretizar, ainda que por pouco tempo os ideais anarquistas de educação e, consequentemente, alguns dos ideais do escolanovismo (ao menos aqueles nos quais vemos as proximidades entre as correntes).

Foram, portanto, movimentos que não só atenderam à demanda educacional da Modernidade, mas que chamaram a atenção para a questão da educação, o que faz-se necessário até os presentes dias.

\section{Referências}

BERNAL, Anastasio Ovejero. Anarquismo espanhol e educação. In: EDUCAÇÃO LIBERTÁRIA - Educação e Revolução na Espanha Libertária. nº 1. IEL. São Paulo: Imaginário. p.9-24. $3^{\circ}$ quadrimestre de 2006.

BEZERRA, Maria Cristina dos Santos. Imigração, Educação e Religião: Um estudo histórico-sociológico do Bairro dos Pires de Limeira, uma comunidade rural de maioria teuto-brasileira. Dissertação de Mestrado. Campinas: Unicamp, 2001.

CAMBI. Franco, História da Pedagogia. Tradução de Álvaro Lorencini. São Paulo: Fundação Editora da UNESP (FEU). 1999.

FERREIRA Jr., Amarílio. História da educação brasileira - História da educação 2. Coleção UAB-UFSCar. Pedagogia. Módulo 02. Edufscar. São Carlos. 2008.

FERRER y Guardia, Francisco. La Escuela Moderna. In: www.antorcha.net/biblioteca_virtual/pedagogia/escuelamoderna/indice.html. Consultado em 07/06/2005. 
GHIRALDELLI Jr., Paulo. Educação e movimento operário. São Paulo: Cortez/ Autores Associados, 1987.

LEI $n^{\circ} 601$ de 18 de setembro de 1850. Dispõe sobre as terras devolutas do Império. Disponível em: <http://www.planalto.gov.br/ccivil_03/LEIS/L0601-1850.htm>. Acesso em 10/09/2009.

MANACORDA. Mario A., História da Educação - da Antigüidade aos nossos dias. Tradução de Gaetano Lo Monaco. 10ª ed. São Paulo: Cortez. 2002.

MANIFESTO dos Pioneiros da Educação Nova. A reconstrução educacional no Brasil - ao povo e ao governo. In: GHIRALDELLI Jr., Paulo. História da Educação Brasileira. 3. ed. São Paulo: Cortez, 2008.

MARX. Karl, ENGELS. Friedrich, Manifesto do Partido Comunista. In: FILHO. Daniel Aarão Reis (org.), et. al. O Manifesto Comunista 150 anos depois. Tradução de Victor Hugo Klagsbrunn. p. 7-41. Rio de Janeiro: Contraponto. 1998.

NAGLE, Jorge. A educação na primeira república. In: FAUSTO, Boris (dir.) História Geral da Civilização Brasileira. Tomo III - O Brasil Republicano - Sociedade e Instituições (1889-1930). 2. ed. v. 2. São Paulo: Difel, 1978.

NAGLE. Jorge. Educação e Sociedade na Primeira Rapública. $1^{a}$ Reimpressão. São Paulo: Editora Pedagógica e Universitária Ltda. (EPU). 1976.

SAVIANI, Dermeval. O legado educacional do "breve século XIX" brasileiro. In: SAVIANI, Dermeval; et. al. O Legado Educacional do Século XIX. 2ªed. p. 8-31.2006.

SAVIANI, Dermeval. O legado educacional do "longo século XX" brasileiro. In:

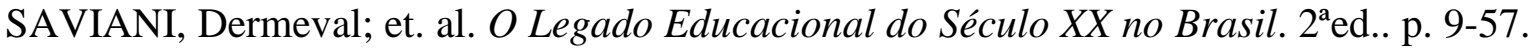
2006b.

\footnotetext{
${ }^{1}$ Doutoranda em História, Filosofia e Sociologia da Educação pelo Programa de Pós-Graduação em Educação da Universidade Federal de São Carlos (PPGE-UFSCar) e professora da Escola Superior de Tecnologia e Educação de Porto Ferreira (ASSER). E-mail: julianaguedes_ufscar_ufscar@yahoo.com.br.

${ }^{2}$ Doutor em Educação pela Universidade Estadual de Campinas (UNICAMP) e professor adjunto do Departamento de Educação da Universidade Federal de São Carlos (UFSCar). Contato: lbezerra@ufscar.br.
}

Recebido em: 13/04/11

Aprovado em: 12/06/11 